\title{
Chromatin, TAFs, and a novel multiprotein coactivator are required for synergistic activation by Spl and SREBP-1a in vitro
}

\author{
Anders M. Näär, ${ }^{1}$ Pierre A. Beaurang ${ }^{1}$ Karen M. Robinson, ${ }^{2}$ Jon D. Oliner, $^{4}$ Daina Avizonis, ${ }^{1}$ \\ Sigrid Scheek, ${ }^{3}$ Jörk Zwicker, ${ }^{1}$ James T. Kadonaga, ${ }^{2}$ and Robert Tjian ${ }^{1,5}$ \\ ${ }^{1}$ Howard Hughes Medical Institute, Department of Molecular and Cell Biology, University of California, Berkeley, \\ California 94720 USA; ${ }^{2}$ Department of Biology, University of California, San Diego, La Jolla, California 92092 USA; \\ ${ }^{3}$ Department of M olecular Genetics, University of Texas Southwestern M edical Center, Dallas, Texas 75235-9046 USA
}

\begin{abstract}
The promoter selectivity factor Spl often cooperates with other enhancer-binding proteins to activate transcription. To study the molecular underpinnings of these regulatory events, we have reconstituted in vitro the synergy observed in vivo between Sp1 and the sterol-regulated factor SREBP-la at the low density lipoprotein receptor (LD LR ) promoter. Using a highly purified human transcription system, we found that chromatin, TAFs, and a novel SREBP-binding coactivator activity, which includes CBP, are all required to mediate full synergistic activation by Sp1 and SREBP-1a. The SREBP-binding domain of CBP inhibits activation by SREBP-1a and Sp1 in a dominant-negative fashion that is both chromatin- and activator-specific. Whereas recombinant CBP alone is not sufficient to mediate activation, a human cellular fraction containing CBP can support high levels of chromatin-dependent synergistic activation. Purification of this activity to near homogeneity resulted in the identification of a multiprotein coactivator, including CBP, that selectively binds to the SREBP-la activation domain and is capable of mediating high levels of synergistic activation by SREBP/Spl on chromatin templates. The development of a reconstituted chromatin transcription system has allowed us to isolate a novel coactivator that is recruited by the SREBP-la activation domain and that functions in concert with TFIID to coordinate the action of multiple activators at complex promoters in the context of chromatin.
\end{abstract}

[Key Words: Transcription; Sp1; chromatin; TAFs; coactivators; SREBPla; CBP; LDLR]

Received June 17, 1998; revised version accepted August 10, 1998.

The transcriptional control regions of many eukaryotic genes harbor multiple enhancer elements recognized by different sequence-specific factors necessary to achieve high levels of transcription (Tjian and Maniatis 1994; Thanos and Maniatis 1995; Sauer and Tjian 1997). The transcription factor Spl is frequently found to be one of the contributing enhancer factors on cognate promoters. Although the molecular mechanisms of Spl activation have been extensively studied (Pascal and Tjian 1991; Hoey et al. 1993; Chen et al. 1994), the function of Sp1 working in concert with other enhancer-binding factors to regulate inducible promoters remains largely unexplored. Recent evidence suggests that many of these inducible genes are governed by gene-selective activators that work synergistically with Sp1 to di rect transcription (Krey et al. 1995; Look et al. 1995; Merika and Orkin

\footnotetext{
${ }^{4}$ Present address: Affymetrix Corporation, Molecular Carcinogenesis Group, Santa Clara, California 95051 USA.

${ }^{5}$ Corresponding author.

E-MAIL jmlim@uclink4.berkeley.edu; FAX (510) 643-9547.
}

1995; Sheridan et al. 1995; Pazin et al. 1996). However, the cofactor requirements and molecular interactions that allow combinatorial regulation by multiple transcriptional activators are poorly understood.

The regulation of the low density lipoprotein receptor (LDLR) gene by cholesterol provides a useful model system to expl ore the molecular mechanisms of synergistic activation by Spl together with other enhancer-binding factors (Goldstein and Brown 1990; Sanchez et al. 1995; Brown and Goldstein 1997). The sequences within the LDLR promoter mediating chol esterol regulation consist of a DNA element recognized by the sterol-responsive element-binding proteins (SREBP-1 and 2) flanked by Sp1-binding sites (Südhof et al . 1987; Dawson et al . 1988; Briggs et al. 1993; Hua et al . 1993; Wang et al. 1993, 1994; Y okoyama et al. 1993; Y ieh et al. 1995). SREBPs belong to the basic/helix-loop-helix class of transcription factors, with the unusual property of being anchored to the ER membrane until released by cholesterol-regulated proteolysis (Brown and Goldstein 1997). Transient transfection experiments suggested that SREBPs and Sp1 can 
function synergistically to activate transcription of the LDLR gene (Sanchez et al. 1995; Athanikar et al. 1997). To investigate the molecular requirements for cooperative activation by SREBP and Sp1, we have attempted to recapitulate SREBP/Spl synergy in an in vitro transcription system.

\section{Results}

Synergistic activation by Sp1 and SREBP-1a in vitro depends on chromatin and TAFs

Because we and others (Sanchez et al . 1995; Athanikar et al. 1997) observed synergistic activation by SREBP-1a/ Sp1 in a Drosophila cell line (Fig. 1A), we initially evaluated transcriptional activation in a crude Drosophila transcription system (Hansen and Tjian 1995). A DNA template containing the SREBP- and Spl-responsive ele- ments from the LDLR promoter was used together with purified recombinant human SREBP-1a (amino acids 1487) corresponding to the active proteolytic cleavage product and recombinant human Spl (Fig. 1C). Interestingly, in contrast to the synergy observed in vivo, only additive levels of transcription were found in the presence of both activators under these conditions in vitro (Fig. 1B, lanes 1-4). N ext, we tested activation by SREBPla and Spl on the LDLR-derived template in a highly purified human in vitro transcription reaction consisting of recombinant TFIIA, TFIIB, TFIIE, TFIIF, immuno-affinity purified TFIID, TFIIH purified over five columns, RNA polymerase II (Pol II) purified from HeLa cell nuclear pellets over three columns, and a cofactor purified from HeLa cell nuclear extract over four columns (Goodrich and Tjian 1994; Materials and Methods). Although this system supported high levels of activated
A

\section{Cell Transfection}

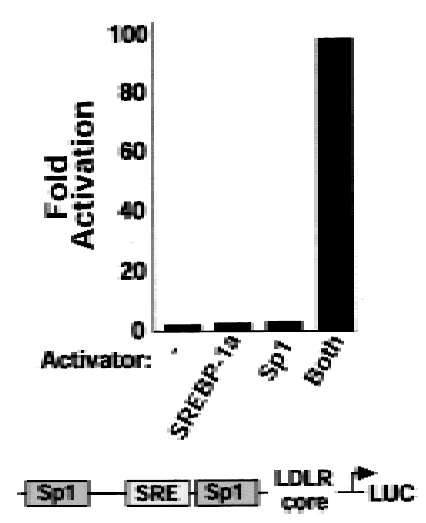

B
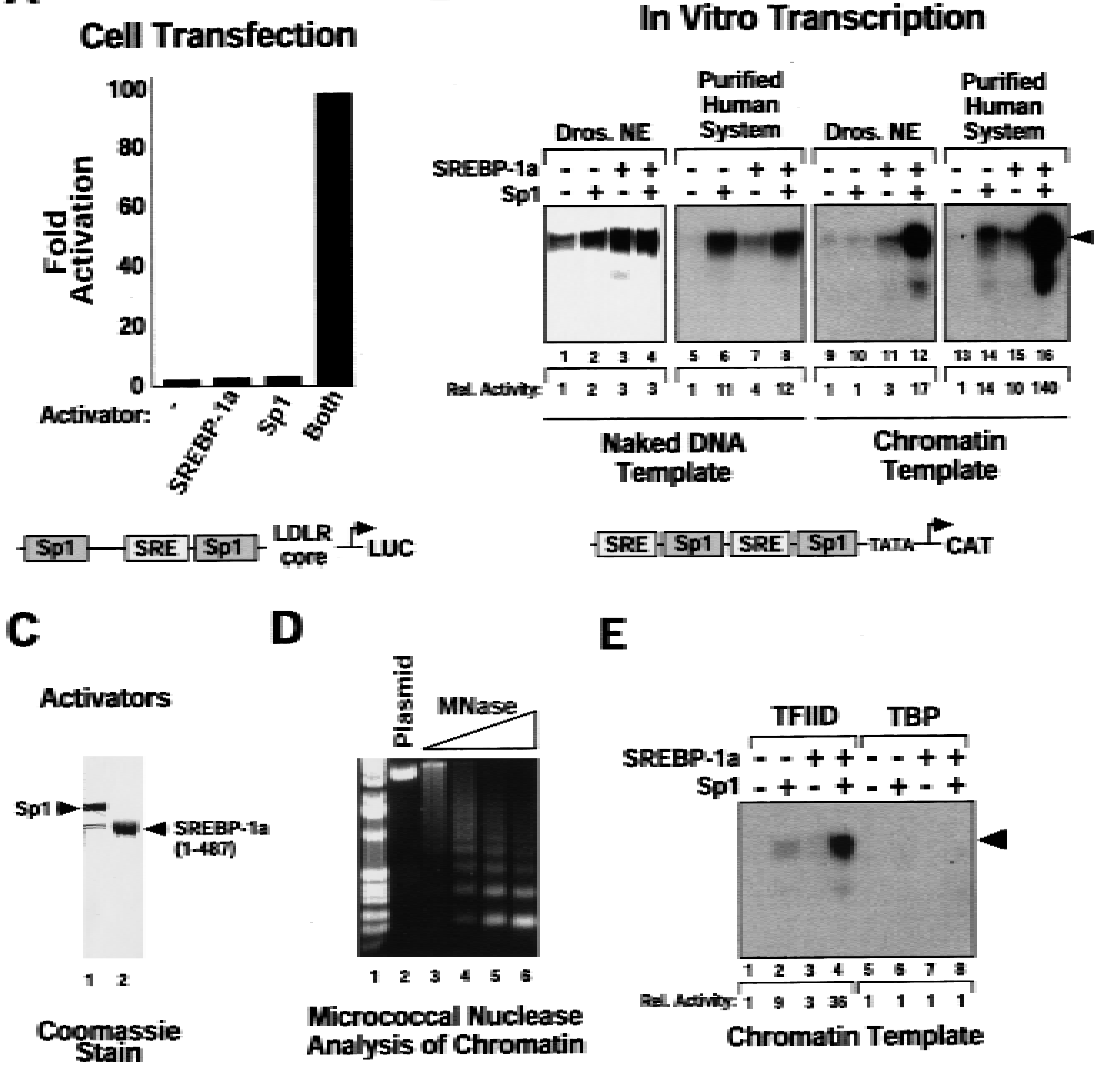

D

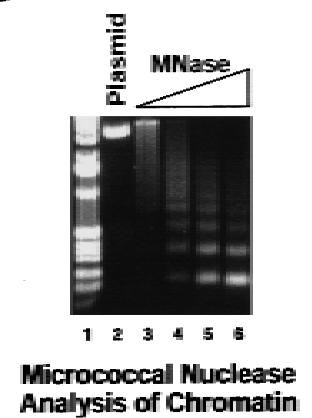

$\mathbf{E}$

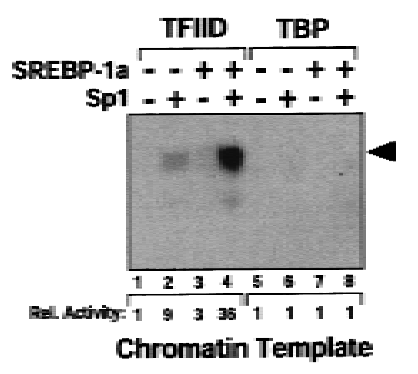

Figure 1. Spl/SREBP-la-dependent transcriptional synergy in a purified in vitro transcription system requires chromatin templates and TAFs. (A) Synergistic activation of transcription by Sp1 and SREBP-1a on the LDL receptor promoter in vivo. Transient transfection of Drosophila Schneider cells with vectors directing expression of human Sp1 and SREBP (SREBP-1a amino acids 1-487) or vector al one (none) together with a reporter construct containing the human LDLR promoter and enhancer sequences fused to the luciferase reporter gene. The organization of the LDLR promoter/enhancer is schematically depicted below the bar graph. (B) Spl and SREBP-la require chromatin for synergistic activation of the LDLRderived template. Phosphorlmager (Fuji) scan and autoradiographs of the in vitro transcription results with no activator added (lanes 1,5,9,13), Sp1 (lanes 2,6,10,14), SREBP-1a (lanes $3,7,11,15$ ), or both activators added (lanes 4,8,12,16). The activity relative to basal transcription (lane 1 , arbitrarily set to 1) is shown bel ow the transcription panels (Rel. Activity). In vitro transcription reactions were assembled by purified activators, a crude Drosophila transcription system (lanes 1-4,9-12) or a highly purified human transcription system (lanes 5-8,1316), and a LDLR promoter-derived reporter plasmid known to support SREBP-1a/Sp1 synergy in vivo. Activators were tested for

activation with the crude Drosophila transcription system (lanes 9-12) or the purified human transcription system (lanes 13-16) by use of naked (lanes 1-8) or chromatin (lanes 6-16) templates. Transcription products were analyzed by primer extension and denaturing PAGE. (C) Purified activators used in transcription reactions. Human recombinant Sp1 (lane 1) was expessed by vaccinia virus infection of HeLa cells and purified from nuclear extract by wheatgerm- and DNA-affinity chromatography. Human His-tagged SREBP-1a (amino acids 1-487, corresponding to the nucl ear proteolytic product) (lane 2) was generated by bacul ovirus infection of Sf9 insect cells and purified over Ni-NTA and DNA affinity columns. (D) Analysis of the LDLR chromatin template by micrococcal nuclease digestion. The DNA template was assembled into chromatin by use of a Drosophila chromatin assembly system and the resulting nucleosomal template was analyzed by digestion with increasing concentrations of micrococcal nuclease. (E) Activation by Spl/SREBP-1a on the LDLR chromatin template requires TAFs. This panel shows the results of in vitro transcription reactions by use of the purified transcription system and chromatin templates containing either no activators (lanes 1,5), Spl (Ianes 2,6), SREBP-1a (lanes 3,7), or both activators (lanes 4,8) in the presence of either immuno-purified human TFIID (Ianes 1-4) or recombinant human TBP (lanes 5-8). 
transcription, no synergy of Spl and SREBP-1a was observed on this naked DN A template (Fig. 1B, lanes 5-8).

One difference between the in vitro and in vivo systems that could influence the coordinate action of multiple activators is the packaging of the in vivo template into chromatin (Pazin et al. 1996). To investigate this possibility, we assembled the LDLR template into chromatin in vitro using a Drosophila chromatin assembly system (Kamakaka et al. 1993) (Fig. 1D) and tested it with SREBP-1a and Spl in the Drosophila nuclear extract-based transcription system. In contrast to the results obtai ned with naked DN A templates, high levels of transactivation were observed only when both activators were added together, whereas little transcription was seen with either activator alone (Fig. 1B, lanes 9-12). When analyzing SREBP-1a/Sp1 activation on chromatin with the purified human transcription system, we also observed a high degree of synergy (Fig. 1B, lanes 13-16). The absolute levels of Sp1/SREBP-1a-dependent transcription on chromatin templates were typically $20 \%-$ $50 \%$ of that observed with naked DN A templates. These results suggest that it is possible to reconstitute transcription reactions in vitro by use of a chromatin template and purified factors that recapitulate synergistic activation by SREBP-1a and Spl on the LDLR-derived template. The purified transcription system also provided the opportunity to investigate various cofactor requi rements for Spl/SREBP-1a activation not possible to address with cruder transcription systems on chromatin templates.

Previous studies identified the TBP-associated factors (TAFs) as potential coactivators for mediating activation in Drosophila and human reconstituted transcription reactions on naked DN A templates (Goodrich et al. 1993; Hoey et al . 1993; Chen et al . 1994; Sauer et al . 1995; Thut et al. 1995). Therefore, we tested whether the TAF subunits of TFIID are also required for activation on chromatin templates. Substituting recombinant human TBP for antibody-affinity purified human TFIID resulted in the loss of activation observed with Spl al one, as well as synergistic activation by Spl and SREBP-1a (Fig. 1E). This finding suggests that TAFs serve important functions in directing transcriptional responses to activators on chromatin templates. In addition to TFIID, high levels of activation with both naked DNA and chromatin templates also require a fraction containing a novel human cofactor important for Spl activation (CRSP, S. Ryu and R. Tjian, unpubl.). However, because Sp1/SREBP-1adependent synergy only occurs on nucleosomal LDLR templates, additional chromatin-specific cofactors may also be required to observe cooperative activation on chromatin templates.

The coactivator CBP is implicated in SREBP-1a/ Spl-dependent chromatin-specific synergy

Our previous investigation of SREBP transcriptional function revealed that the coactivator CBP interacts with the SREBP activation domain (Oliner et al. 1996). The reconstitution of SREBP-1a and Spl synergy on the
LDLR template in a defined in vitro transcription system allowed us to address the potential involvement of CBP in chromatin-dependent synergy in vitro. To examine this, we first used a combination of molecular deletion analysis and proteolytic digestion of SREBP-1a and CBP to identify the sequences responsible for the interaction between SREBP and CBP. Our studies of the activation domain of SREBP-1a revealed that the amino-terminal 50 amino acids were sufficient for interaction with CBP (Fig. 2A,B). This region is the most highly conserved within the activation domains of SREBPs. Additionally, a natural splicing variant of SREBP-1 that lacks the first 29 amino acids (SREBP-1c) is severely compromised for transcriptional activation, indicating the functional importance of this region in activation by SREBPs (Shimano et al. 1997), and truncation of the first 51 amino acids inactivated SREBP-1a in transfection studies (Sato et al. 1994).

In a previous study, we found that the first 682 amino acids of CBP bind strongly to SREBP-1a (Oliner et al. 1996). Partial Staphylococcal V8 protease digestion of this region resulted in the isolation of a stable 135amino-aci d fragment spanning amino acids 548-682 that was selectively retained on a SREBP affinity column. As expected, a recombinant CBP548-682 polypeptide also interacted strongly with the SREBP-la activation domain (Fig. 2B) and was predicted to compete with endogenous CBP for interaction with SREBP-1a and potentially disrupt SREBP-1a/Spl cooperativity in a dominant-negative fashion. To test this possibility, we added increasing concentrations of the CBP peptide to in vitro transcription reactions reconstituted with the LDLR chromatin template. The SREBP-1a/Sp1-mediated transcriptional activation was strongly inhibited by the CBP peptide in a dose-dependent manner (Fig. 2C). The chromatin-dependent synergistic activation by $\mathrm{NF}-\kappa \mathrm{B}$ and Spl on the HIV-LTR was used as a control for the specificity of the inhibition. Because NF-кB interacts with a different portion of CBP (P. Beaurang, D. Avizonis, and R. Tjian, unpubl.), N F-kB/Spl synergy should be refractory to inhibition by the SREBP-specific CBP peptide. Addition of CBP548-682 did not significantly affect N F$\kappa B / S p 1$ synergy on the HIV-LTR chromatin template, attesting to the specificity of the peptide (Fig. 2D).

As an additional control, we also carried out experiments with increasing amounts of the CBP peptide added to transcription reactions with naked DNA templates. The CBP peptide failed to significantly inhibit either basal or activated transcription on the naked DNA template (Fig. 2E). These results taken together suggest that an activity, possibly related to CBP, present in our chromatin-based transcription system is a functionally important target for the SREBP-1a activation domain specifically in the context of the chromatin-dependent synergy with Spl on the LDLR promoter template.

Reconstitution of SREBP-1a/Spl activation on chromatin requires a CBP-containing activity

To identify and characterize the chromatin-dependent cofactor activity, we next attempted to modify the tran- 
A

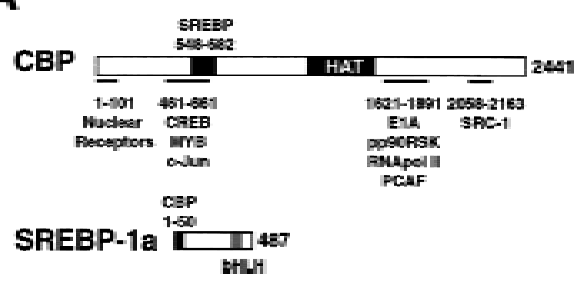

B

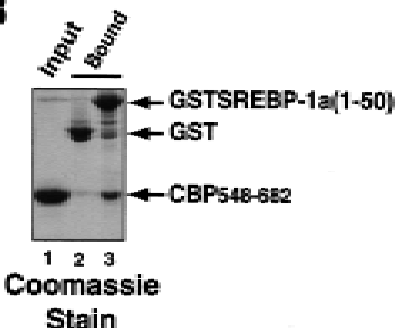

Stain
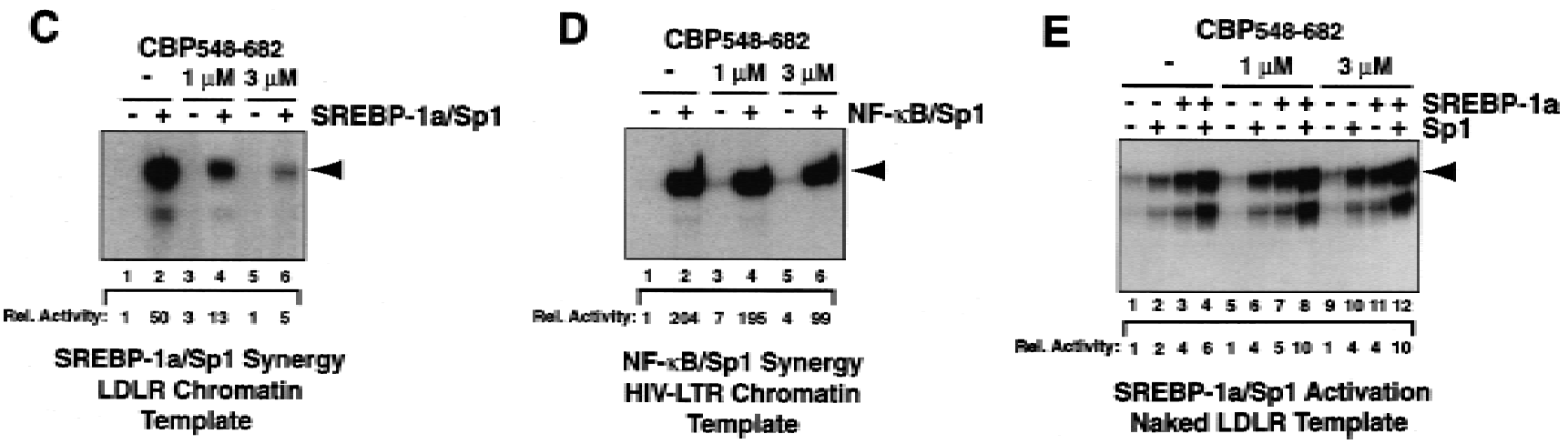

Figure 2. Interaction between CBP and SREBP-1a is implicated in chromatin-specific transcriptional synergy. (A) Schematic depiction of the domains of CBP that are involved in protein-protein interactions and HAT activity. The CBP domain interacting with the amino-terminal 50 amino acids of SREBP-1a was determined by partial V8 protease digestion. The regions that are involved in interaction between CBP and SREBP-1a are highlighted by solid boxes in both proteins. (B) Binding assay with CBP548-682 and GST-SREBP-1a (amino acids 1-50). Purified CBP548-682 was incubated with gl utathione-agarose beads prebound to either GST (Iane 2) or GST-SREBP-1a (amino acids 1-50) (lane 3). Lane 1 shows the input CBP548-682 (50\%). The binding of CBP548-682 to the beads was analyzed by SDS-PAGE and visualized by Coomassie staining. (C) Effect of adding CBP548-682 protein (lanes 3-6) to a highly purified transcription system using the LDLR-promoter chromatin template and SREBP-1a/Sp1. (D) Effect of adding CBP548-682 protein (lanes 3-6) to a highly purified transcription system using a HIV-LTR chromatin template and NF-кB/Spl. (E) The same CBP548-682 protein fragment was added (lanes 5-12) to a highly purified transcription system using a naked LDLR-promoter template and SREBP-1a/Spl.

scription reaction so that it gained responsiveness to the addition of exogenous cofactor/CBP activity. Because the dominant-negative inhibition by the CBP peptide indicated that our chromatin transcription reactions contain an activity that may be related to CBP, and immunoblotting results showed that the purified transcription system is devoid of CBP (data not shown), we suspected that a CBP-like activity is present in the S-190 chromatin assembly extract. To limit this potential cofactor contribution, we reconstituted transcription reactions with low levels of S-190 extract. Decreasing the amount of S-190 extract used to assemble chromatin by $50 \%$ did not significantly affect chromatin assembly; however, transcriptional activation by SREBP-1a/Sp1 was substantially reduced (Fig. 3A, cf. lanes 1 and 2 and 5 and 6 ). Additionally, purification of the chromatin template over a sucrose gradient reveal ed a requirement for the S-190 extract to observe synergistic activation (data not shown). These results suggest that the S-190 extract provides one or more cofactor(s) important for SREBP-1a/ $\mathrm{Spl}$ activation. To determine whether addition of a human CBP-containing cofactor could substitute for the limiting cofactor(s) in the S-190 extract, we partial ly purified CBP from HeLa cell nuclear extract by phosphocellulose chromatography and assayed for stimulatory activity in the cofactor-dependent chromatin transcription system. Whereas the CBP-containing cofactor fraction [phosphocellulose fraction eluting at $0.5 \mathrm{~m}$ salt (PC $0.5 \mathrm{~m}$ ) stimulated transcription modestly when added to reactions with high levels of S-190 extract, addition of the PC $0.5 \mathrm{M}$ fraction to reactions reconstituted with low amounts of S-190 extract resulted in greatly increased transcriptional response (Fig. 3A, cf. Ianes 1-4 with lanes 5-8). Because RNA Pol II and the general transcription factors TFIIB, TFIIE, TFIIF, and TFIIH are not limiting in our transcription reactions (data not shown), this result suggests that the CBP-containing fraction can at least partially replace the S-190 activity.

$\mathrm{N}$ ext, we wished to test whether CBP alone was sufficient to reconstitute this cofactor activity. When increasing concentrations of recombinant CBP (rCBP) (Fig. 3B) were added to transcription reactions with the S-190limited chromatin template, no stimulation of transcriptional activation by SREBP-1a/Spl was observed (Fig. $3 C$, cf. lanes 1 and 2 and 5-10). At higher concentrations of $\mathrm{rCBP}$, we observed apparent squelching of activated transcription. Similarly, recombinant P/CAF, which has been shown to interact with CBP, either al one or in combination with rCBP failed to enhance activation (data not shown). This is in contrast to the strong stimulatory ac- 
Figure 3. A CBP-containing fraction is required for full transactivation by SREBP$1 \mathrm{a} / \mathrm{Sp1}$ on chromatin templates and cannot be replaced by recombinant CBP. (A) A human cofactor fraction stimulates transcriptional activation by SREBP-1a/Spl on chromatin template. The transcriptional response to a CBP-containing fraction (PC $0.5 \mathrm{M}$ ) derived from HeLa cell nuclear extract was tested with chromatin templates assembled by use of high (lanes 1-4) or low (lanes 5-8) amounts of S-190 extract in the absence (lanes $1,3,5,7$ ) or presence of SREBP-1a/Sp1 (lanes 2,4,6,8). (B) Analysis of purified recombinant CBP. Recombinant Flag epitope-tagged CBP ( $\mathrm{rCBP}$ ) was expressed in Sf9 insect cells by baculovirus infection and affinity purified from nuclear extracts by use of M 2 Flag beads. The peptide-eluted $\mathrm{rCBP}$ was analyzed on a $7 \%$ SDS-polyacrylamide gel followed by protein staining with Coomassie brilliant blue. (A rrowhead) Migration of full-length rCBP; (asterisk) position of a CBP proteolytic product. (C) Stimulation of Spl/ SREBP-1a-dependent activation on chromatin by a CBP-containing fraction, but not by rCBP. The effect of adding a CBPcontaining fraction from HeLa cell nuclear extract (PC 0.5 M) (lanes 3,4) to S-190-limited chromatin transcription reactions performed in the absence (lanes 1,3) or presence (lanes 2,4$)$ of SREBP-1a/Spl (1-2 nM) is shown. Recombinant CBP (lanes 5-10) were added in the indicated nanogram amounts to chromatin transcription reactions performed in the absence (lanes $5,7,9)$ or presence (lanes $6,8,10)$ of activators $(1-2$ nM ). (Arrowhead) Migration of transcription/primer extension products. (D) Depletion of CBP from the PC $0.5 \mathrm{M}$ fraction by the activation domain of SREBP-1a. The CBP-containing cofactor fraction (PC $0.5 \mathrm{M}$ ) (lane 1) was passed over glutathione-Sepharose loaded either with GST or GST-SREBP-1a (amino acids 1-50). The bound (lanes 2,3) and flowthrough (FT; lanes 4,5) fractions were analyzed by Western blotting with anti-CBP antiserum (Santa Cruz Biotechnology). (E) A coactivator activity is depleted from the PC $0.5 \mathrm{M}$ fraction by the SREBP-1a activation domain. The GST and GST-SREBP-1a (amino acids 1-50)-flowthrough fractions were tested for stimulatory activity in the in vitro transcription reactions on chromatin template. Depletion by GST did not significantly diminish cofactor activity (lanes 3,4), whereas the cofactor activity in the GST-SREBP-1a (amino acids 1-50)-depleted fraction was dramatically reduced (lanes 5,6).

tivity observed with the PC $0.5 \mathrm{M}$ fraction (Fig. 3C, lanes $3,4)$. The recombinant CBP interacts strongly with the activation domain of SREBP-1a and mediates histone acetyl transferase (HAT) activity (Bannister and Kouzarides 1996; Ogryzko et al . 1996) (data not shown), suggesting that recruitment of HAT activity is not sufficient for full transcriptional activation by SREBP-1a/Spl on chromatin templates. Additionally, recombinant $\mathrm{p300}$, demonstrated previously to enhance activation by the estrogen receptor in a crude chromatin transcription system (Kraus and Kadonaga 1998), was not capable of replacing the CBP fraction in our purified chromatin transcription system (data not shown). Taken together, these experiments suggest that $\mathrm{CBP} / \mathrm{p} 300$ al one or in combination with $\mathrm{P} / \mathrm{CAF}$ are not sufficient to mediate transcriptional activation by SREBP-1a/Spl on chromatin templates, and indicate that other activities present in the CBPcontaining fraction may provide important functions.
Because the activation domain of SREBP-la binds to CBP and perhaps other activities, we attempted to use it as an affinity resin to deplete the CBP-containing cofactor fraction of stimulatory activity. After passing the cofactor fraction over the SREBP-affinity resin or a GST control resin, we analyzed the bound and flowthrough fractions by CBP immunoblotting (Fig. 3D). We found that $>95 \%$ of CBP present in the cofactor fraction input was depleted (Fig. 3D, lane 5) and remained bound to the activation domain of SREBP-la even after extensive washing of the resin (Fig. 3D, lane 3). In contrast, the GST control resin did not bind any CBP (Fig. 3D, lanes 2,4$)$. When testing the two flowthrough fractions for stimulation of transcription in the SREBP-1a/Sp1dependent chromatin transcription system, the GST flowthrough fraction contained cofactor activity, whereas the SREBP activation-domain flowthrough was significantly depleted of cofactor activity (Fig. 3E). These 
results suggest that an activity present in the cofactor fraction binds to and is depleted by the SREBP-1a activation domain. Although we have obtained multiple lines of evidence suggesting that the coactivator CBP may be an important mediator of chromatin-dependent synergy by SREBP-1a/Sp1, our results could al so be consistent with the notion that other factors present in the CBP-containing fraction contribute to the coactivator activity.

Purification and functional characterization of a CBP-containing coactivator

The depletion of coactivator activity from the partially purified CBP fraction by GST -SREBP-1a (amino acids 150 ) indicated the feasibility of using the SREBP-affinity column to purify this coactivator. HeLa cell nuclear extract was initially applied to the GST -SREBP (amino acids 1-50) affinity resin or a control resin consisting of the glutamine-rich activation domain A of Spl fused to GST . After extensive washing, the bound fractions were analyzed by SDS-PAGE followed by silver staining. The results showed that a series of polypeptides (280-30 kD), including CBP (immunoblot not shown), interacted strongly with the GST-SREBP (amino acids 1-50) affinity resin, whereas no specific binding to the GST-SplA control beads was detected (Fig. 4A). Similar results were obtained when using the PC $0.5 \mathrm{M}$ fraction in place of the Hela cell nuclear extract (data not shown). Preliminary immunobl otting results indicated that trace amounts of P/CAF, SRC-1/NCOA1, GRIP-1/NCOA2, and RNA Pol II were detected in some GST-SREBP (amino acids 1-50) pulldowns (data not shown), however, these proteins do not appear to be stoichiometric components of this activity. RNA Pol II is not limiting in our transcription reactions, thus this source of RNA Pol II is unlikely to contribute significantly to transcriptional activation in this system. No binding of SWI/SN F proteins or RNA helicase $A$ was detected (data not shown). These results suggest that this CBP-containing coactivator is distinct from previously identified CBP complexes and holoRNA Pol II activities (Chakravarti et al. 1996; Kamei et al. 1996; Kee et al. 1996; Y ang et al. 1996; Zhang et al. 1996; Heery et al. 1997; N akajima et al. 1997a,b; Perkins et al . 1997; Torchia et al. 1997; Korzus et al . 1998; Kurokawa et al. 1998).

Because CBP has been reported to harbor HAT activity (Bannister and Kouzari des 1996; Ogryzko et al. 1996), we tested whether the SREBP-1a activation domain could recruit HAT activity. Strong HAT activity was detected only with the SREBP-associated fraction, whereas the Spl-activation domain did not recruit any HAT activity (Fig. 4B). Because SREBP-1a appears to recruit HAT activity, we tested the effect of adding acetyl COA and the histone deacetylase inhibitor trichostatin A (TSA) to SREBP-1a/Spl-driven chromatin transcription reactions. Addition of TSA resulted in a small (less than twofold) dose-dependent increase in levels of activated transcription, whereas addition of acetyl CoA had little influence on transcription (data not shown), suggesting that his-
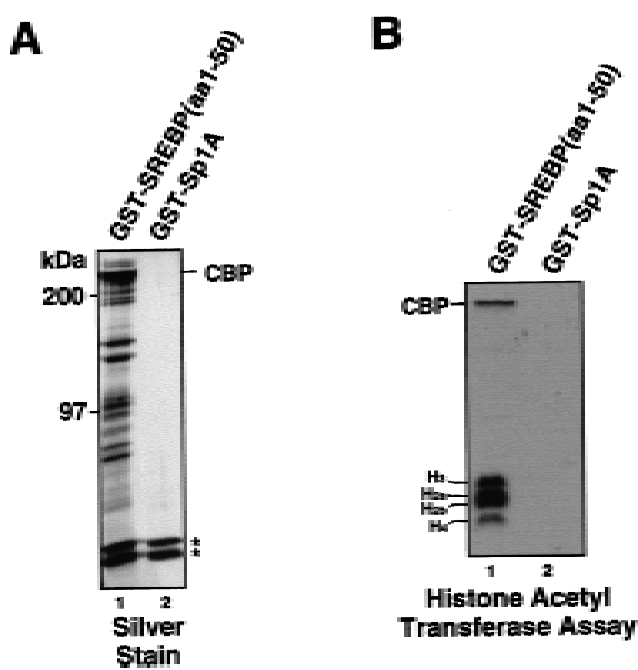

Figure 4. A CBP-containing multiprotein coactivator associates selectively with the activation domain of SREBP-1a and mediates HAT activity. (A) A series of proteins in addition to CBP associate sel ectively with the SREBP-la activation domain. HeLa cell nuclear extract was incubated with affinity resins containing the activation domains of SREBP-1a (GST-SREBP-1a amino acids 1-50) (lane 1) or Spl (GST-SplA amino acids 83262) (lane 2) and after extensive washing, the bound fractions were analyzed by SDS-PAGE foll owed by silver staining (shown) and immunoblotting. The migration of CBP is indicated. The two asterisks mark the positions of nonspecific proteins binding to the GST portion of the fusion proteins. (B) The SREBP activation domain recruits HAT activity. Pulldowns from HeLa nucl ear extract with GST-SREBP (amino acids 1-50) (lane 1) and GST-Sp1A (amino acids 83-262) (lane 2) were tested for HAT activity by incubating the washed beads with purified Drosophila core histones, ${ }^{3} \mathrm{H}$-labeled acetyl $\mathrm{CoA}$, and $\mathrm{N}$ a Butyrate. The reactions were analyzed by separation on a $15 \%$ SDS polyacrylamide gel followed by autoradiography. The migration of core histones and CBP is indicated at left

tone acetylation is unlikely to significantly contribute to the cofactor activity.

Next, we examined whether the affinity-purified SREBP-binding factors could substitute for the crude PC $0.5 \mathrm{M}$ cofactor fraction when added to transcription re actions. The CBP-containing coactivator was purified from the PC $0.5 \mathrm{~m}$ fraction by the SREBP activation domain affinity resin and eluted by use of $0.1 \%$ deoxycholate. These two chromatographic steps resulted in purification of the coactivator to near homogeneity (increase in specific activity $\sim 5000$-fold). We estimate that the SREBP affinity-purified coactivator is at least 1000-fold purified relative to the PC $0.5 \mathrm{M}$ cofactor fraction (Fig. $5 A$ ). When the highly purified SREBP-binding proteins were added to the S-190-limited chromatin transcription system, strong stimulation of SREBP-1a/Spl synergistic activation was observed (Fig. 5B, lanes 1-4 and 5-8), comparable with the enhancement observed with the crude PC 0.5 m cofactor fraction (Fig. 3A, lanes 5-8). In contrast, addition of the el uted SREBP-binding proteins to transcription reactions with naked DNA templates resulted in little effect on basal or activated transcription 
Figure 5. An affinity-purified coactivator mediates chromatin-specific activation by SREBP-1a/Sp1. (A) Purification of the coactivator to near homogeneity by phosphocelIulose and SREBP-la-activation domain-affinity chromatography. HeLa cell nuclear extract (lane 2) was first passed over a phosphocellulose column and the main peak of cofactor activity was found in the $0.5 \mathrm{M}$ fraction (PC $0.5 \mathrm{M}$, lane 3). The cofactor fraction (PC $0.5 \mathrm{M}$ ) was then passed over the GSTSREBP-1a (amino acids 1-50) resin, and specifically bound proteins were eluted by buffer containing $0.1 \%$ deoxycholate (lane 4). Similar results were observed when using the CBP548-682 peptide or glutathione for elution. The eluate was analyzed on a 7\% SDS-polyacrylamide gel followed by silver staining. The relative amounts of coactivator units (as judged by titration of coactivator in the SREBP-1a/Sp1-dependent chromatin transcription system with chromatin assembled by use of low S-190 extract) loaded onto the gel are shown below lanes 3 and 4. Molecular weight markers (lane 1) are indicated at left. The migration of CBP (as judged by immunoblotting) and other specific SREBP-binding proteins is indicated at right. $\mathrm{N}$ on-specific proteins that do not consistently copurify with coactivator activity are indicated by asterisks above CBP and below 77 markers. (B) The coactivator is required for full activation by SREBP-1a/Spl in S-190-limited chromatin transcription reactions. Shown is the effect of adding the affinity-purified coactivator (lanes 5-8) to S-190 limited chromatin transcription reactions in the absence of activators (lanes 1,5), presence of Spl (lanes 2,4,6,8) or presence of SREBP-1a (lanes 3,4,7,8). (Arrowhead) Migration of transcription/primer extension products. (C) The coactivator does not affect transcription from naked DN A templates. Transcription reactions performed with naked DN A templates in the absence (Ines 1-4) or presence (lanes 5-8) of affinity-purified coactivator. SREBP-1a (lanes 3,4,7,8) and Spl (lanes 2,4,6,8) were added as indicated. (Arrowhead) Migration of transcription/primer extension products.

(Fig. 5C). These findings suggest that a multiprotein coactivator capable of selective binding to the activation domain of SREBP-la participates in mediating SREBP$1 \mathrm{a} / \mathrm{Spl}$ activation in the context of chromatin.

\section{Discussion}

We have reconstituted Sp1/SREBP-1a -dependent transcriptional synergy at the LDLR promoter in vitro. Our results indicate that the coordi nate activation by $\mathrm{Spl}$ and SREBP-la requires the LDLR template to be assembled into chromatin. Using a purified human transcription system, we found that multiple distinct coactivators are necessary to mediate chromatin-dependent synergy by SREBP-1a/Spl, including TAFs, and a highly purified CBP-containing multiprotein coactivator that directly binds to the activation domain of SREBP-1a (Fig. 6). The TAF requirement for high levels of activation by Spl and SREBP-la may be explained at least partly by the welldocumented interactions between Spl and $\mathrm{hTAF}_{11} 130$ in recruiting TFIID to the promoter (Chen et al. 1994; Gill et al. 1994). Because SREBP-la was not found to contact TFIID, or other components of the core transcriptional machinery (data not shown), cooperativity cannot be explained by direct targeting of multipl e general transcription factors (GTFs) (Sauer et al. 1995). SREBP-1a/Sp1 cooperativity may be a function of recruitment of both a CBP-containing coactivator and TFIID to the promoter (Fig. 6). This dual requirement of a CBP-containing coactivator and TAFs for activation of transcription by SREBP-1a and Sp1 is reminiscent of the cofactor interactions utilized by the CAMP/PKA-activated transcrip-
Figure 6. Model for cofactor requirements necessary for synergistic activation by SREBP-1a and Spl on the LDLR chromatin template. Chromatin-mediated repression of transcription could be alleviated by the recruitment of a CBP-containing coactivator by SREBP, which may facilitate access of the transcriptional machinery to a nucleosomal template. Also depicted is the well-characterized recruitment of TFIID by $\mathrm{Spl}$ via $\mathrm{TAF}_{11} 130$ to nucleate formation of the preinitiation complex or aid in reinitiation of transcription. The HAT activity of CBP may participate in remodeling of the nucleosomal structure, whereas the function of the other components of the SREBP-binding coactivator remains to be established.

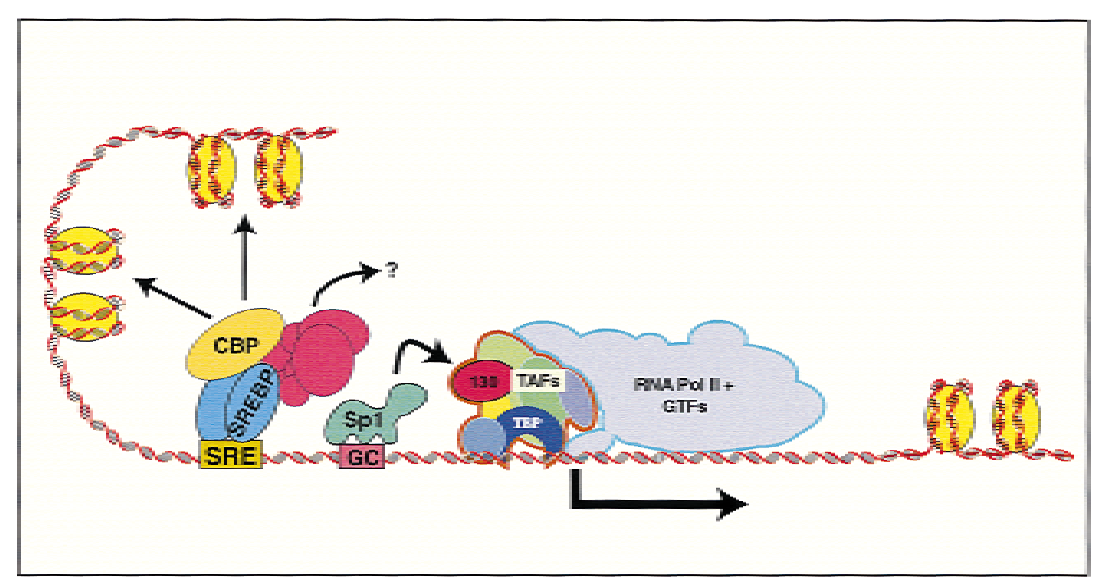


tion factor CREB. Both recruitment of TFIID and CBP are required for $C R E B$ activation, thus it appears that $C R E B$ embodies functions of both Sp1 and SREBP-1a (Chrivia et al. 1993; Ferreri et al. 1994; Nakajima et al. 1997b). Although CREB appears to activate transcription efficiently on naked DNA templates and interacts with a CBP-RNA Pol II complex (Kee et al. 1996; Nakajima et al. 1997a), our results suggest that the CBP-containing coactivator recruited by SREBP-1a performs a chromatin-dependent function required for SREBP-1a/Spl synergy.

Chromatin-mediated regulation of transcription may be a strategy utilized by several classes of transcription factors responding to various signaling pathways. N uclear receptors, STATs, and Jun/Fos, among others have been shown recently to functionally interact with CBP and may require histone-modifying activities to regulate their target genes (Arias et al. 1994; Kwok et al. 1994; Bannister and Kouzarides 1995; Bannister et al. 1995; Chakravarti et al. 1996; Kamei et al. 1996; Zhang et al. 1996; Heery et al . 1997; Torchia et al . 1997; Korzus et al. 1998; Kraus and Kadonaga 1998; Kurokawa et al. 1998). Additionally, NF-кB was found to interact with p300/CBP (Perkins et al. 1997) and was recently shown to synergize with Spl on the HIV-LTR in a chromatindependent manner (Pazin et al. 1996; Sheridan et al. 1997). Interestingly, p300/CBP recruited by N F-kB is associated with a cyclin-dependent kinase activity (Perkins et al. 1997), suggesting that multiple biochemical activities may be contained within p300/CBP complexes. We are currently investigating whether the functional requirements for NF-kB and SREBP-la synergy with Sp1 are similar.

In vitro DN ase I footprinting showed strong cooperativity in binding of Spl and SREBP-la to the nucleosomal LDLR template, and in vivo DMS footprinting studies also indicated a sterol-regulated cooperative binding of Spl and SREBPs to the LDLR promoter in vivo (data not shown). These footprinting results together with the multiple cofactor requirements suggest that cooperative recruitment of factors to the promoter may contribute to the mechanism of transcription activation in a chromatin-regulated environment. Prel iminary footprinting experiments suggest that the SREBP binding coactivator exert little effect on DN A binding by SREBP-1a and Spl (data not shown). Similarily, little influence on the chromatin structure in the promoter was seen by the SREBP coactivator (data not shown). Chromatin-specific factors distinct from the CBP-containing coactivator, including ATP-dependent nucleosomal remodeling activities such as SWI/SN Fs, NURF, CHRAC, ACF, and RSC (Laurent and C arlson 1992; Y oshinaga et al . 1992; Imbalzano et al. 1994; Kwon et al. 1994; Peterson et al. 1994; Tsukiyama and Wu 1995; Cairns et al. 1996; Ito et al. 1997; Varga-Weisz et al. 1997), may al so play important roles in activation by Spl/SREBP-1a by serving in a more general capacity to facilitate binding of activators and the core transcriptional machinery to chromatin templates. We suspect that one or more of these remodeling activities is present in the S-190 chromatin assembly extract and may contribute to the requirement observed for the S-190 extract to activate transcription on chromatin templates. Future studies will be aimed at elucidating the role of ATP-dependent remodeling factors in the synergi stic activation by SREBP-1a/Spl on the LDLR chromatin template.

The CBP-containing coactivator harbors HAT activity and appears to be necessary for full activation by SREBP$1 \mathrm{a} / \mathrm{Spl}$ on chromatin templates, while having little effect when using naked DN A templates. It is tempting to speculate that acetylation of histones by CBP may facilitate access of SREBP-1a and Sp1 to nucleosomal templates and aid in the recruitment of the preinitiation complex to the core promoter (Fig. 6). However, at present, we cannot conclude that the HAT activity in the CBP-containing coactivator is required for SREBP-1a/ Spl synergy on chromatin templates. Addition of acetyl CoA and/or the histone deacetylase inhibitor TSA to the transcription reactions resulted in less than twofold effects, suggesting that our transcription system may already contain acetyl COA and may belimited in histone deacetylase activity, or the histones could al ready be acetylated. It is al so concei vable that HAT activity is not critical for the synergistic activation by SREBP-1a/Sp1 on chromatin templates. Further studies of the role of HAT activity in the chromatin-dependent synergistic activation by SREBP-1a/Spl will likely require the use of purified chromatin templates, purified or recombinant histone deacetylases and the development of HAT specific inhibitors. Other enzymatic activities, such as kinases, could also be associated with the CBP-containing coactivator and might modify histones or components of the transcriptional apparatus.

We are currently cloning and characterizing the genes encoding the polypeptides in the SREBP-1a activation domain-binding coactivator to elucidate their functional contribution in mediating SREBP-1a/Sp1 synergistic activation on chromatin templates. The active coactivator fraction contains CBP and at least 10 other stoichiometric polypeptides ranging from 220 to $30 \mathrm{kD}$. Prel iminary peptide sequencing revealed that several of these proteins are novel human gene products. The eventual development of a purified chromatin transcription system should provide us with val uable tools for future detailed molecular studies of chromatin-dependent mechanisms of transcription regulation of natural genes by multiple activators.

\section{Materials and methods}

\section{Chromatin assembly}

The LDLR-derived template plasmid was assembled into chromatin as described (Kamakaka et al. 1993). Briefly, Drosophila embryo cytosolic high-speed supernatant (S-190) extract, Drosophila core histones purified from embryos by use of hydroxylapatite, Mg/ATP, and an ATP-regenerating system were added to supercoiled DNA template and assembly was performed for $4.5 \mathrm{hr}$ at $27^{\circ} \mathrm{C}$. The resulting chromatin was analyzed with $0.31,0.93,2.8$, and 8.3 units of micrococcal nuclease ( $\mathrm{M} \mathrm{N}$ ase, Sigma) digestion for $10 \mathrm{~min}$ at $20^{\circ} \mathrm{C}$. A typical nucleo- 
somal ladder was observed when separated on agarose-TBE gels and visualized with EtBr staining.

\section{In vitro transcription}

Transcription reactions were performed basically as described in (Kamakaka et al. 1993). After $4 \mathrm{hr}$ and $30 \mathrm{~min}$ of chromatin template assembly, SREBP-1a (1-5 nм) or N F-кB p65/p50 heterodimers (4-5 nM) and Sp1 (2-5 nM) were added and al lowed to incubate with the template for $30 \mathrm{~min}$. For control transcription on naked DN A templates, the activators were added to identical amounts of template (0.6 nM ) in the presence or absence of S-190 extract $(30 \mu \mathrm{g})$ and $\mathrm{Mg} / \mathrm{ATP}$ for $30 \mathrm{~min}$ at $27^{\circ} \mathrm{C}$. HeLa nuclear extract, Drosophila H 0.4 M fraction (Hansen and Tjian 1995) or purified GTFs (Goodrich and Tjian 1994) were then added and allowed to incubate for $10 \mathrm{~min}$ at $27^{\circ} \mathrm{C}$. Transcription was initiated by addition of NTPs ( $0.5 \mathrm{~mm}$ final concentration) in a final volume of $50 \mu \mathrm{l}$ and allowed to proceed for $30 \mathrm{~min}$ at $27^{\circ} \mathrm{C}$. The products were analyzed by primer extension (Lillie and Green 1989). For studies of the effect of adding acetyl CoA and TSA to SREBP-1a/Sp1-driven transcription reactions with the LDLR chromatin template, acetyl CoA (1, 10, or $100 \mu \mathrm{m})$ or TSA $(0.01,0.1$, or $1 \mu \mathrm{M})$ were added al one or in combination.

\section{Expression and purification of GTFs}

The human recombinant/highly purified transcription system is composed of recombinant human TFIIA (5 ng), TFIIB (5 ng), TFIIE56 (2.5 ng), TFIIE34 (10 ng), TFIIF (7.5 ng), and RN A Pol II (24 ng) purified to the phenyl column stage from HeLa nuclear pellets as described (Goodrich and Tjian 1994), TFIIH (15 ng) purified from either HeLa nuclear or cytoplasmic extracts as described (Goodrich and Tjian 1994), immunopurified TFIID (25 $\mathrm{ng}$ ) and purified CRSP-containing cofactor fraction (100 ng). Recombinant human TFIIA was generated as described (Ozer et al. 1994). Recombinant human TFIIB, TFIIE56, TFIIE34, and TFIIF were expressed and purified as described (Goodrich and Tjian 1994). Human TFIID was immunoprecipitated with mAb 3A6, raised against $h T A F_{11} 130$, from either $P C 1.0 \mathrm{M}$ or from a DE-52 $1.0 \mathrm{M} \mathrm{KCl}$-eluted fraction from PC $1.0 \mathrm{M}$. The complex was washed in $0.8 \mathrm{M} \mathrm{KCl}$ HEG [20 mM HEPES (pH 7.6), $0.1 \mathrm{~mm}$ EDTA, $10 \%$ glycerol] and eluted with an epitope-containing peptide in $0.15 \mathrm{M} \mathrm{KCI}$ HEGN (HEG with $0.1 \% \mathrm{NP}-40$ ). The CRSP-containing cofactor fraction was purified from PC $1.0 \mathrm{M}$, followed by DE-52 FT at $0.1 \mathrm{M}$, POROS-heparin gradient, and finally over POROS-HS. The activity el uted between $0.38 \mathrm{M}$ and $0.5 \mathrm{M} \mathrm{KCl} \mathrm{HEG}$ and dialyzed to $0.1 \mathrm{M} \mathrm{KCl} \mathrm{HEG}$. Purification, cloning, and definition of CRSP will be published el sewhere (S. Ryu and R. Tjian, in prep.).

Generation of SREBP-1a and Spl activation domain fusions to GST

The first 50 amino acids of human SREBP-1a and the activation domain A of Sp1 (amino acids 83-262) were amplified by PCR and ligated to pGEX-2TK (Pharmacia). The resulting GST fusion was expressed in Escherichia coli (BL21) and purified over glutathione-Sepharose beads.

\section{Identification of the SREBP-binding domain of CBP}

His-tagged recombinant CBP1-682 was expressed in E. coli (BL21). Cells were lysed by French press in $100 \mathrm{~mm} \mathrm{NaCl}, 25$ $\mathrm{mm}$ Imidazole, $20 \mathrm{~mm}$ Tris $\mathrm{HCl}(\mathrm{pH} 7.8), 1 \mathrm{~mm}$ PMSF, $1 \mathrm{~mm}$ DTT. The recombinant protein was then purified by nickel affinity chromatography followed by POROS-HS ion exchange chromatography. The protein was dialyzed against $100 \mathrm{~mm}$ $\mathrm{NaCl}, 20 \mathrm{~mm}$ Tris $\mathrm{HCl}$ (pH 7.8). Purified CBP1-682 was then partially digested by endoproteinase Glu-C (Staphlococcus aureus V8 protease; Promega) at $0.01 \mu \mathrm{g}$ of enzyme per $100 \mu \mathrm{g}$ of CBP1-682 for $2.5 \mathrm{hr}$ at $37^{\circ} \mathrm{C}$ resulting in fragments ranging from $5 \mathrm{kD}-60$ daltons. These fragments were then tested for binding to GST-SREBP1a (amino acids 1-50). The smallest fragment that specifically bound the SREBP fusion was concentrated and partially purified by POROS-HS ion exchange chromatography followed by reverse-phase HPLC. Its exact sequence was determined by amino-terminal sequencing and electro-spray mass spectroscopy to be amino acids 548-682. The DNA sequence corresponding to CBP548-682 was amplified by PCR and subcloned into the pAED4 plasmid.

\section{Expression and purification of CBP548-682}

Recombinant CBP548-682 was expressed in E. coli (BL21 pLysS) which were lysed by French press in $25 \mathrm{~mm} \mathrm{NaCl}, 20 \mathrm{~mm}$ MES (pH 6.0), $2.5 \mathrm{~mm}$ EDTA, $1 \mathrm{~mm}$ DTT, $1 \mathrm{~mm}$ AEBSF. DNA was partially removed by $0.2 \%$ poly(ethylenimine) precipitation. The supernatant was first passed through a fastflow Q-sepharose column then loaded onto a FPLC POROS-HS column. Bound CBP548-682 was eluted by salt gradient 20-500 mm $\mathrm{NaCl}$ in buffer [20 mM MES (pH 6.0), $2.5 \mathrm{~mm}$ EDTA, $1 \mathrm{~mm}$ DTT ]. Recombinant CBP548-682 (5 $\mu \mathrm{g})$ was added to GST - or GST-SREBP-1a (amino acids 1-50) beads and incubated with gentle mixing for $30 \mathrm{~min}$ at $4^{\circ} \mathrm{C}$. The beads were washed extensively with $0.1 \mathrm{M} \mathrm{KCl} \mathrm{HEGN}$ and analyzed by SDS-PAGE and Coomassie Brilliant blue staining. For peptide inhibition of transcription, the various activators (1-2 nM) were incubated with purified recombinant CBP548-682 in $0.1 \mathrm{M} \mathrm{KCl} \mathrm{HEG} \mathrm{for}$ $20 \mathrm{~min}$ at room temperature prior to addition to the transcription reactions.

\section{Generation of recominant CBP}

The CDN A encoding mouse CBP was inserted into a baculovirus transfer vector (pAcSG2) in frame with two amino-terminal FLAG-epitope (Kodak) sequences. Baculovirus was produced, screened for CBP expression, and amplified, according to protocol supplied by the manufacturer (Invitrogen). One liter of Sf9 cells was infected with CBP baculovirus (5 MOI) for $48 \mathrm{hr}$. $\mathrm{N}$ uclear extract was prepared from pelleted cells (Dignam et al. 1983) and incubated with $500 \mu \mathrm{l}$ of FLAG-antibody beads (Kodak) for $4 \mathrm{hr}$ at $4^{\circ} \mathrm{C}$. After extensive washing, recombinant CBP was eluted using $0.5 \mathrm{mg} / \mathrm{ml}$ FLAG peptide in $0.1 \mathrm{M} \mathrm{KCl} \mathrm{HEG}$ with $0.01 \%$ N P-40.

Purification and identification of proteins binding to the SREBP-1a activation domain

HeLa nuclear extract was loaded onto P11 phosphocellulose in $0.1 \mathrm{M} \mathrm{KCl} \mathrm{HEG}$. The column was eluted with $0.2 \mathrm{M}, 0.5 \mathrm{M}$, and $1.0 \mathrm{M} \mathrm{KCl} \mathrm{HEG} \mathrm{steps.} \mathrm{Cofactor} \mathrm{activity} \mathrm{and} \mathrm{CBP} \mathrm{immunoreac-}$ tivity was found to copurify in the PC $0.5 \mathrm{M}$ fraction, which was dialyzed to $0.1 \mathrm{M} \mathrm{KCl} \mathrm{HEG}$. One milliliter of HeLa nuclear extract or $500 \mu \mathrm{l} \mathrm{PC} 0.5 \mathrm{~m}$ fraction was applied to $20 \mu \mathrm{l}$ of either GST, GST-Sp1 (amino acids 83-262), or GST-SREBP-1a (amino acids 1-50) beads. Gentle mixing was performed at $4^{\circ} \mathrm{C}$ for $2 \mathrm{hr}$, the flowthrough fraction collected and the beads washed extensively with 0.3 and $0.5 \mathrm{M} \mathrm{KCI} \mathrm{HEGN} \mathrm{(HEG} \mathrm{with} 0.1 \%$ NP-40) and analyzed by SDS-PAGE followed by silver staining and immunoblotting with affinity-purified anti-CBP, anti-RNA Pol II, anti-N-CoAl and 2, anti-P/CAF, anti-RHA, and anti-SWI/ SN Fs. For the depletion experiments, $500 \mu$ l of PC $0.5 \mathrm{M}$ was 
mixed with $100 \mu$ l of GST or GST -SREBP-1a (amino acids 1-50) beads for $2 \mathrm{hr}$, then the supernatant was transferred to $100 \mu \mathrm{l}$ of fresh beads and mixed for another $2 \mathrm{hr}$ at $4^{\circ} \mathrm{C}$. The doubledepleted PC $0.5 \mathrm{M}$ was then tested for cofactor activity in chromatin transcription reactions and for presence of CBP by immunoblotting. For elution of the GST-SREBP-1a (amino acids 1-50) associated proteins, 2 vol of $0.1 \mathrm{M} \mathrm{KCI} \mathrm{HEGN} \mathrm{with} 0.1 \%$ deoxycholate or $250 \mu \mathrm{M}$ CBP548-682 peptide was added, and nutated at $4^{\circ} \mathrm{C}$ for $4 \mathrm{hr}$. The supernatant was collected and dialyzed against $0.1 \mathrm{M} \mathrm{KCl} \mathrm{HEG} \mathrm{for} 4 \mathrm{hr}$.

\section{Evaluation of HAT activity in the GST pull-downs}

One milliliter of HeLa nuclear extract was incubated with $20 \mu \mathrm{l}$ of GST-SREBP (amino acids 1-50) and GST-SplA (amino acids 83-262) beads followed by extensive washing as described above. HAT activity was assayed by incubating the beads with 1-2 $\mu \mathrm{g}$ of purified Drosophila core histones, $1 \mu \mathrm{Ci}{ }^{3} \mathrm{H}$-labeled acetyl CoA, and $10 \mathrm{~mm} \mathrm{~N}$ a butyrate in buffer $\mathrm{A}$ [50 mM Tris- $\mathrm{HCl}$ (pH 8.0), $50 \mathrm{~mm} \mathrm{KCl}, 0.5 \mathrm{~mm}$ EDTA, 10\% glycerol, $1 \mathrm{~mm}$ DTT, $1 \mathrm{~mm}$ PM SF] for $30 \mathrm{~min}$ at $27^{\circ} \mathrm{C}$. The reactions were analyzed by separation on a $15 \%$ SDS-polyacrylamide gel followed by Coomassie staining and autoradiography for 5 days.

\section{Acknowledgments}

We thank D. Reinberg, P. Lieberman, and R. Goodman for providing plasmids encoding hTFIIA $\alpha \beta$, hTFIIA $\gamma$, and mouse CBP, respectively. The pAED4 plasmid was a gift of D.S. Doering. The N F-кB subunits were kindly supplied by Z. Cao. We thank $\mathrm{Y}$. N akatani for the kind gift of P/CAF antiserum. The antisera directed toward $\mathrm{N}-\mathrm{COA} 1$ and 2 were generously provided by M.G. Rosenfeld. The RHA antiserum was a kind gift of $M$. M ontminy. Antisera directed towards hSWI/SN F subunits were kindly provided by $\mathrm{G}$. Crabtree. We thank T. Osborne for providing the SREBP-1a expression plasmid and LDLR reporter construct used in the transfection studies. We thank L. Kraus for reagents, protocols, and helpful suggestions. We thank D. Rio, P. Kaufman, B. Lemon, I. Haviv, M. Rabenstein, T. O'Brien, and G. Cutler for critical reading of the manuscript. A.M.N. and J.D.O. are fellows with the Damon Runyon-Walther Winchell Cancer Research Foundation, J.Z. and S.S. receive support from the Deutsche Forschungsgemeinschaft, D.A. is a M erck Fellow with the Life Sciences Research Foundation, and K.R. receives a fellowship from the Medical Research Council of Canada. This work was funded in part by $\mathrm{N}$ ational Institutes of Heal th grant GM 46995 to J.T.K. and grants CA 25417 and HL20948.

The publication costs of this article were defrayed in part by payment of page charges. This article must therefore be hereby marked 'advertisement' in accordance with 18 USC section 1734 solely to indicate this fact.

\section{References}

Arias, J., A.S. Alberts, P. Brindle, F.X. Claret, T. Smeal, M. Karin, J. Feramisco, and M. Montminy. 1994. Activation of CAMP and mitogen responsive genes relies on a common nuclear factor. Nature 370: 226-229.

Athanikar, J.N., H.B. Sanchez, and T.F. Osborne. 1997. Promoter selective transcriptional synergy mediated by sterol regulatory element binding protein and Sp1: A critical role for the Btd domain of Sp1. Mol. Cell. Biol. 17: 5193-5200.

Bannister, A.J. and T. Kouzarides. 1995. CBP-induced stimulation of c-Fos activity is abrogated by E1A. EMBO J. 14: 47584762.
-_- 1996. The CBP co-activator is a histone acetyltransferase. Nature 384: 641-643.

Bannister, A.J., T. Oehler, D. Wilhel m, P. Angel, and T. Kouzarides. 1995. Stimulation of C-Jun activity by CBP: c-Jun residues Ser63/73 are required for CBP induced stimulation in vivo and CBP binding in vitro. Oncogene 11: 2509-2514.

Briggs, M.R., C. Y okoyama, X. Wang, M.S. Brown, and J.L. Goldstein. 1993. N uclear protein that binds sterol regulatory element of Iow density lipoprotein receptor promoter. I. Identification of the protein and delineation of its target nucleotide sequence. J. Biol. Chem. 268: 14490-14496.

Brown, M.S. and J.L. Goldstein. 1997. The SREBP pathway: Regulation of cholesterol metabolism by proteolysis of a membrane-bound transcription factor. Cell 89: 331-340.

Cairns, B.R., Y. Lorch, Y. Li, M. Zhang, L. Lacomis, H. Erdjument-Bromage, P. Tempst, J. Du, B. Laurent, and R.D. Kornberg. 1996. RSC, an essential, abundant chromatin-remodeling complex. Cell 87: 1249-1260.

Chakravarti, D., V.J. LaM orte, M.C. N elson, T. N akajima, I.G. Schulman, H. Juguilon, M. Montminy, and R.M. Evans. 1996. Role of CBP/P300 in nuclear receptor signalling. Nature 383: 99-103.

Chen, J.L., L.D. Attardi, C.P. Verrijzer, K. Yokomori, and R. Tjian. 1994. Assembly of recombinant TFIID reveals differential coactivator requirements for distinct transcriptional activators. Cell 79: 93-105.

Chrivia, J.C., R.P. Kwok, N. Lamb, M. Hagiwara, M.R. Montminy, and R.H. Goodman. 1993. Phosphorylated CREB binds specifically to the nuclear protein CBP. Nature 365: 855-859.

Dawson, P.A., S.L. Hofmann, D.R. van der Westhuyzen, T.C. Sudhof, M.S. Brown, and J.L. Goldstein. 1988. Sterol-dependent repression of low density lipoprotein receptor promoter mediated by 16-base pair sequence adjacent to binding site for transcription factor Sp1. J. Biol. Chem. 263: 3372-3379.

Ferreri, K., G. Gill, and M. M ontminy. 1994. The CAM P-regulated transcription factor CREB interacts with a component of the TFIID complex. Proc. Natl. Acad. Sci. 91: 1210-1213.

Gill, G., E. Pascal, Z.H. Tseng, and R. Tjian. 1994. A glutaminerich hydrophobic patch in transcription factor Spl contacts the dTAFIII10 component of the Drosophila TFIID complex and mediates transcriptional activation. Proc. Natl. Acad. Sci. 91: 192-196.

Goldstein, J.L. and M.S. Brown. 1990. Regulation of the mevaIonate pathway. Nature 343: 425-430.

Goodrich, J.A., T. Hoey, C.J. Thut, A. Admon, and R. Tjian. 1993. Drosophila TAFII40 interacts with both a VP16 activation domain and the basal transcription factor TFIIB. Cell 75: 519-530.

Hansen, S.K. and R. Tjian. 1995. TAFs and TFIIA mediate differential utilization of the tandem Adh promoters. Cell 82: $565-575$.

Goodrich, J.A. and R. Tjian. 1994. Transcription factors IIE and $\mathrm{IIH}$ and ATP hydrolysis direct promoter clearance by RNA polymerase II. Cell 77: 145-156.

Heery, D.M., E. Kalkhoven, S. Hoare, and M.G. Parker. 1997. A signature motif in transcriptional co-activators mediates binding to nuclear receptors. Nature 387: 733-736.

Hoey, T., R.O. Weinzierl, G. Gill, J.L. Chen, B.D. Dynlacht, and R. Tjian. 1993. Molecular cloning and functional analysis of Drosophila TAF110 reveal properties expected of coactivators. Cell 72: 247-260.

Hua, X., C. Yokoyama, J. Wu, M.R. Briggs, M.S. Brown, J.L. Goldstein, and X. Wang. 1993. SREBP-2, a second basic-helix-loop-helix-leucine zipper protein that stimulates transcription by binding to a sterol regulatory element. Proc. 
Natl. Acad. Sci. 90: 11603-11607.

Imbalzano, A.N., H. Kwon, M.R. Green, and R.E. Kingston. 1994. Facilitated binding of TATA-binding protein to nucleosomal DNA. Nature 370: 481-485.

Ito, T., M. Bulger, M.J. Pazin, R. Kobayashi, and J.T. Kadonaga. 1997. ACF, an ISWI-containing and ATP-utilizing chromatin assembly and remodeling factor. Cell 90: 145-155.

Kamakaka, R.T., M. Bulger, and J.T. Kadonaga. 1993. Potentiation of RN A polymerase II transcription by Gal4-VP16 during but not after DNA replication and chromatin assembly. Genes \& Dev. 7: 1779-1795.

Kamei, Y., L. Xu, T. Heinzel, J. Torchia, R. Kurokawa, B. Gloss, S.C. Lin, R.A. Heyman, D.W. Rose, C.K. Glass, and M.G. Rosenfeld. 1996. A CBP integrator complex mediates transcriptional activation and AP-1 inhibition by nuclear receptors. Cell 85: 403-414.

Kee, B.L., J. Arias, and M .R. M ontminy. 1996. Adaptor-mediated recruitment of RNA polymerase II to a signal-dependent activator. J. Biol. Chem. 271: 2373-2375.

Korzus, E., J. Torchia, D.W. Rose, L. Xu, R. Kurokawa, E.M. M clnerney, T.M. Mullen, C.K. Glass, and M.G. Rosenfeld. 1998. Transcription factor-specific requirements for coactivators and their acetyltransferase functions. Science 279: 703-707.

Kraus, W.L. and J.T. Kadonaga. 1998. p300 and estrogen receptor cooperatively activate transcription via differential enhancement of initiation and reinitiation. Genes \& Dev. 12: 331-342.

Krey, G., A. M ahfoudi, and W. Wahli. 1995. Functional interactions of peroxisome proliferator-activated receptor, retinoid-X receptor, and Sp1 in the transcriptional regulation of the acyl-coenzyme-A oxidase promoter. Mol. Endocrinol. 9: $219-231$.

Kurokawa, R., D. Kalafus, M.H. Ogliastro, C. Kioussi, L. Xu, J. Torchia, M.G. Rosenfeld, and C.K. Glass. 1998. Differential use of CREB binding protein-coactivator complexes. Science 279: $700-703$.

Kwok, R.P., J.R. Lundblad, J.C. Chrivia, J.P. Richards, H.P. Bachinger, R.G. Brennan, S.G. Roberts, M.R. Green, and R.H. Goodman. 1994. N uclear protein CBP is a coactivator for the transcription factor CREB. Nature 370: 223-226.

Kwon, H., A.N. Imbalzano, P.A. Khavari, R.E. Kingston, and M.R. Green. 1994. Nucleosome disruption and enhancement of activator binding by a human SW1/SN F complex. Nature 370: 477-481.

Laurent, B.C. and M. Carlson. 1992. Yeast SNF2/SWI2, SN F5, and SN F6 proteins function coordinately with the gene-spe cific transcriptional activators GAL4 and Bicoid. Genes \& Dev. 6: 1707-1715.

Lillie, J.W. and M.R. Green. 1989. Transcription activation by the adenovirus Ela protein. Nature 338: 39-44.

Look, D.C., M.R. Pelletier, R.M. Tidwell, W.T. Roswit, and M.J. Holtzman. 1995. Stat1 depends on transcriptional synergy with Sp1. J. Biol. Chem. 270: 30264-30267.

Merika, M. and S.H. Orkin. 1995. Functional synergy and physical interactions of the erythroid transcription factor GATA-1 with the Kruppel family proteins Sp1 and EKLF. Mol. Cell. Biol. 15: 2437-2447.

Nakajima, T., C. U chida, S.F. Anderson, C.G. Lee, J. Hurwitz, J.D. Parvin, and M. Montminy. 1997a. RNA helicase A me diates association of CBP with RNA polymerase II. Cell 90: 1107-1112.

Nakajima, T., C. Uchida, S.F. Anderson, J.D. Parvin, and M. Montminy. 1997b. Analysis of a CAM P-responsive activator reveals a two-component mechanism for transcriptional induction via signal-dependent factors. Genes \& Dev. 11: 738747.
Ogryzko, V.V., R.L. Schiltz, V. Russanova, B.H. Howard, and Y. N akatani. 1996. The transcriptional coactivators p300 and CBP are histone acetyltransferases. Cell 87: 953-959.

Oliner, J.D., J.M. Andresen, S.K. Hansen, S. Zhou, and R. Tjian. 1996. SREBP transcriptional activity is mediated through an interaction with the CREB-binding protein. Genes \& Dev. 10: 2903-2911.

Ozer, J., P.A. M oore, A.H. Bolden, A. Lee, C.A. Rosen, and P.M. Lieberman. 1994. M olecular cloning of the small $(\alpha)$ subunit of human TFIIA reveals functions critical for activated transcription. Genes \& Dev. 8: 2324-2335.

Pascal, E. and R. Tjian. 1991. Different activation domains of Spl govern formation of multimers and mediate transcriptional synergism. Genes \& Dev. 5: 1646-1656.

Pazin, M.J., P.L. Sheridan, K. Cannon, Z. Cao, J.G. Keck, J.T. Kadonaga, and K.A. Jones. 1996. N F-кB-mediated chromatin reconfiguration and transcriptional activation of the HIV-1 enhancer in vitro. Genes \& Dev. 10: 37-49.

Perkins, N.D., L.K. Felzien, J.C. Betts, K. Leung, D.H. Beach, and G.J. N abel. 1997. Regulation of NF-кB by cyclin-dependent kinases associated with the p300 coactivator. Science 275: 523-527.

Peterson, C.L., A. Dingwall, and M.P. Scott. 1994. Five SWI/ SN F gene products are components of a large multisubunit complex required for transcriptional enhancement. Proc. Natl. Acad. Sci. 91: 2905-2908.

Sanchez, H.B., L. Yieh, and T.F. Osborne. 1995. Cooperation by sterol regulatory element-binding protein and Spl in sterol regulation of low density lipoprotein receptor gene. J. Biol. Chem. 270: 1161-1169.

Sato, R., J. Yang, X. Wang, M.J. Evans, Y.K. Ho, J.L. Goldstein, and M.S. Brown. 1994. Assignment of the membrane attachment, DNA binding, and transcriptional activation domains of sterol regulatory element-binding protein-1 (SREBP-1). J. Biol. Chem. 269: 17267-17273.

Sauer, F. and R. Tjian. 1997. Mechanisms of transcriptional activation: Differences and similarities between yeast, Drosophila, and man. Curr. Opin. Genet. Dev. 7: 176-181.

Sauer, F., S.K. Hansen, and R. Tjian. 1995. Multiple TAFIIs directing synergistic activation of transcription. Science 270: 1783-1788.

Sheridan, P.L., C.T. Sheline, K. Cannon, M.L. Voz, M.J. Pazin, J.T. Kadonaga, and K.A. Jones. 1995. Activation of the HIV-1 enhancer by the LEF-1 HMG protein on nucleosome-assembled DN A in vitro. Genes \& Dev. 9: 2090-2104.

Sheridan, P.L., T.P. Mayall, E. Verdin, and K.A. Jones. 1997. Histone acetyltransferases regulate HIV-1 enhancer activity in vitro. Genes \& Dev. 11: 3327-3340.

Shimano, H., J.D. Horton, I. Shimomura, R.E. Hammer, M.S. Brown, and J.L. Goldstein. 1997. Isoform 1c of sterol regulatory el ement binding protein is less active than isoform la in livers of transgenic mice and in cultured cells. J. Clin. Invest. 99: 846-854.

Südhof, T.C., D.R. Van der Westhuyzen, J.L. Goldstein, M.S. Brown, and D.W. Russell. 1987. Three direct repeats and a TATA-like sequence are required for regulated expression of the human low density lipoprotein receptor gene. J. Biol. Chem. 262: 10773-10779.

Thanos, D. and T. Maniatis. 1995. Virus induction of human IFN beta gene expression requires the assembly of an enhanceosome. Cell 83: 1091-1100.

Thut, C.J., J.L. Chen, R. Klemm, and R. Tjian. 1995. p53 transcriptional activation mediated by coactivators TAFII40 and TAFII60. Science 267: 100-104.

Tjian, R. and T. Maniatis. 1994. Transcriptional activation: A complex puzzle with few easy pieces. Cell 77: 5-8. 
Torchia, J., D.W. Rose, J. Inostroza, Y. Kamei, S. Westin, C.K. Glass, and M.G. Rosenfeld. 1997. The transcriptional coactivator $\mathrm{p} / \mathrm{CIP}$ binds CBP and mediates nucl ear-receptor function. Nature 387: 677-684.

Tsukiyama, T. and C. Wu. 1995. Purification and properties of an ATP-dependent nucleosome remodeling factor. Cell 83: $1011-1020$.

Varga-Weisz, P.D., M. Wilm, E. Bonte, K. Dumas, M. Mann, and P.B. Becker. 1997. Chromatin-remodelling factor CHRAC contains the ATPases ISWI and topoisomerase II. Nature 388: 598-560.

Wang, X., M.R. Briggs, X. Hua, C. Y okoyama, J.L. Goldstein, and M.S. Brown. 1993. N uclear protein that binds sterol regulatory element of low density lipoprotein receptor promoter. II. Purification and characterization. J. Biol. Chem. 268: 14497-14504.

Wang, X., R. Sato, M.S. Brown, X. Hua, and J.L. Goldstein. 1994. SREBP-1, a membrane-bound transcription factor released by sterol-regulated proteolysis. Cell 77: 53-62.

Yang, X.J., V.V. Ogryzko, J. Nishikawa, B.H. Howard, and Y. Nakatani. 1996. A p300/CBP-associated factor that competes with the adenoviral oncoprotein E1A. Nature 382: 319-324.

Yieh, L., H.B. Sanchez, and T.F. Osborne. 1995. Domains of transcription factor Spl required for synergistic activation with sterol regulatory el ement binding protein 1 of Iow density lipoprotein receptor promoter. Proc. Natl. Acad. Sci. 92: 6102-6106.

Yokoyama, C., X. Wang, M.R. Briggs, A. Admon, J. Wu, X. Hua, J.L. Goldstein, and M.S. Brown. 1993. SREBP-1, a basic-helixloop-helix-leucine zipper protein that controls transcription of the low density lipoprotein receptor gene. Cell 75: 187197.

Yoshinaga, S.K., C.L. Peterson, I. Herskowitz, and K.R. Yamamoto. 1992. Roles of SWI1, SWI2, and SWI3 proteins for transcriptional enhancement by steroid receptors. Science 258: 1598-1604.

Zhang, J.J., U. Vinkemeier, W. Gu, D. Chakravarti, C.M. Horvath, and J.E. Darnell, Jr. 1996. T wo contact regi ons between Statl and CBP/p300 in interferon gamma signaling. Proc. Natl. Acad. Sci. 93: 15092-15096. 


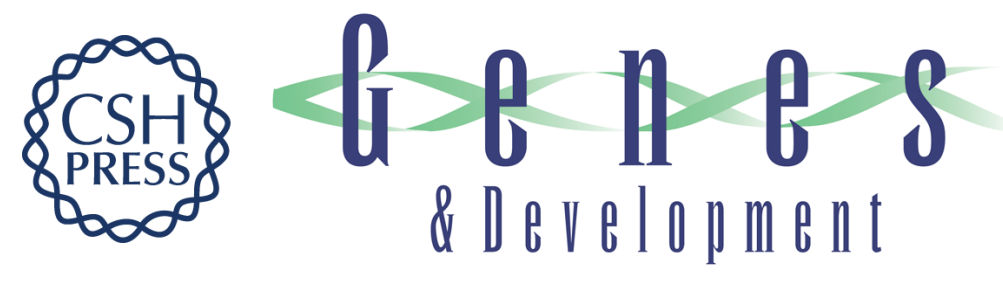

\section{Chromatin, TAFs, and a novel multiprotein coactivator are required for synergistic activation by Sp1 and SREBP-1a in vitro}

Anders M. Näär, Pierre A. Beaurang, Karen M. Robinson, et al.

Genes Dev. 1998, 12:

Access the most recent version at doi:10.1101/gad.12.19.3020

References This article cites 66 articles, 32 of which can be accessed free at: http://genesdev.cshlp.org/content/12/19/3020.full.html\#ref-list-1

License

Email Alerting

Receive free email alerts when new articles cite this article - sign up in the box at the top Service right corner of the article or click here.

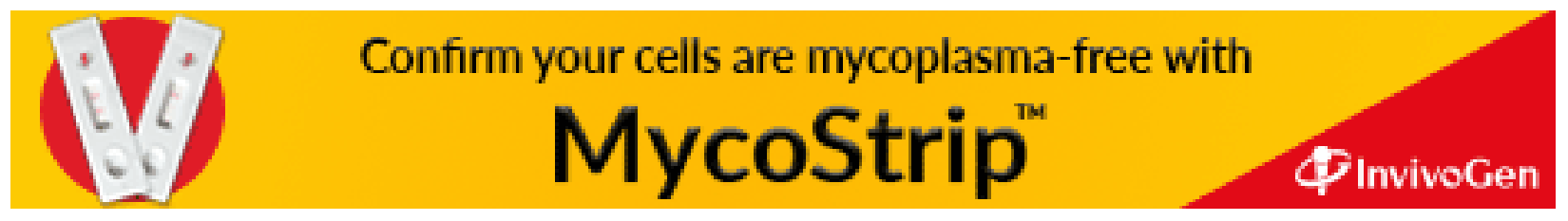

